$\xi=$ 줄

\title{
Squamous odontogenic tumor: A rare tumor of premolar region of mandible: a case report
}

\author{
Suzan Salem ${ }^{1 *}$, Rana Alamri $^{2}$, Islam Saad ${ }^{3}$ \\ ${ }^{1}$ Department of Oral Surgery, Maxillofacial and Diagnostic Science, College of Dentistry, Qassim University, KSA \\ ${ }^{2}$ College of Dentistry, Taibah University, KSA \\ ${ }^{3}$ Department of Periodontology and Oral Medicine, College of Dentistry, Qassim University, KSA \\ *Corresponding author E-mail: Dr.Suzan.Salem@qudent.org
}

\begin{abstract}
Background: The squamous odontogenic tumor is characterized as an extremely uncommon amiable neoplasm, beginning from the rests of Malassez, gingival surface epithelium or from remainders of the dental lamina. The squamous odontogenic tumor was first described by Pullon et al. (1975), since that time only 50 cases in the English-language literature in which the microscopic characteristics are frequently very well demonstrated. The characteristic radiographic appearance is that of a triangular shaped unilocular radiolucency associated with the roots of erupted teeth and has a predilection for the anterior maxilla and the posterior mandible.

Methods: We reported a case of squamous odontogenic tumor occurring in a 40-year-old female in the premolar are of mandible with common localization and appearance. The tumor underwent surgical excision for histopathological examination and confirming diagnosis, followed by total resection of the tumor and using demineralized freeze-dried bone allograft and collagen membrane to fill defect.

Results: Histological examination revealed a proliferation of mature stratified squamous epithelial islands in a dense fibrous connective stroma and the diagnosis of squamous odontogenic tumor was confirmed.

Conclusions: Although squamous odontogenic tumor is a rare tuomr which arise from the rest of Malassez, but it should be listed as a differential diagnosis and confirmed with histopathological examination, it should be treated first conservatively, but upon recurrence a more aggressive line of treatment is to be followed.
\end{abstract}

Keywords: Benign; Unilocular Triangle Radiolucency; Squamous Odontogenic Tumour

\section{Introduction}

The squamous odontogenic tumor (SOT) is an uncommon kind of neoplasm much of the time situated inside the jaws. In 1975, Pullon et al. recognized this condition and revealed it without precedent for a series of 6 case (Pullon et al. 1975). This benign tumor has a slow and continuous growth that might invade the trabecular bone, affecting the cortical bone and penetrating adjoining structures (Goldblatt et al. 1982). Three main types are recognized: intraosseous, mural (mural SOT like-proliferation in a cyst) and extraosseous form, aggressive and multifocal form have also been reported. recently, it has been reported to be associated with calcifying epithelial odontogenic tumor (Oliveira et al. 2006, Ruhin et al. 2007).

As indicated by the World Health Organization (WHO) in 2005 SOT was defined as a benign epithelium odontogenic tumor but locally infiltrative neoplasm comprising of islands of well differentiated squamous epithelium in a fibrous stroma. The epithelial islands incidentally demonstrate foci of central cystic degeneration (Barnes et al. 2005, Badni et al. 2012, Bansal \& Joshi 2013).

SOT affects a wide age, ranging from eight to seventy-four-yearold (Badni et al. 2012). The premolar-molar region of the mandible and the incisor-premolar area of the maxilla, with almost same distribution between maxilla and mandible (Adebiyi et al. 2006, Tarsitano et al. 2012).
Clinically, SOT shows up as an asymptomatic swelling in the alveolar process and the affected teeth show a variable degree of mobility with mild discomfort to percussion. In most cases, the tumor is incidentally discovered on routine dental radiographs, which reveal a generally well-defined, radiolucent, unilocular, triangular-shaped image between or along the roots of adjacent teeth, resembling severe periodontal bone loss (Parmar et al. 2011) Histologically it is formed by multiple islands of squamous, nonkeratinized, well-differentiated and rounded epithelial cells scattered in a fibrous tissue stroma without any indication of cellular atypia (Badni et al. 2012 ).

\section{Case description and results}

A 40-year-old female patient reported to outpatient dental clinic of College of Dentstry, Qassim University suffering from teeth mobility in the right premolar region of the mandible for last six months. Upon Clinical examination, a mild degree of expansion of the buccal surface, the overlying mucosa appeared normal, and on palpation the area was slightly compressible with no pain. The mandibular right first and second premolar were mobile.

Digital panoramic radiograph (Figure 1) showed radiolucency with severe localized alveolar bone loss between first and second premolar of right mandible, which was associated with root divergence. The patient didn't reveal a history of presence of an odontogenic abscess. No surgical intervention had been performed in this area that would suggest a possible residual cyst or apical 
scar. The suggested diagnosis was therefore a periacpical cyst associated to any of these teeth. On the basis of the location of the lesion, the X-ray study and diagnostic study images, the differential diagnosis included lateral periodontal cyst, keratocystic odontogenic cyst, ossifying fibroma, and other less common odontogenic tumors.

In view of this clinical appearance, the initial management consisted of partial removal of the lesion (incisional biopsy), which confirm the diagnosis of SOT. Then, total resection of the tumor and curettage were performed, followed by the using demineralized freeze-dried bone allograft and collagen membrane to fill defect.

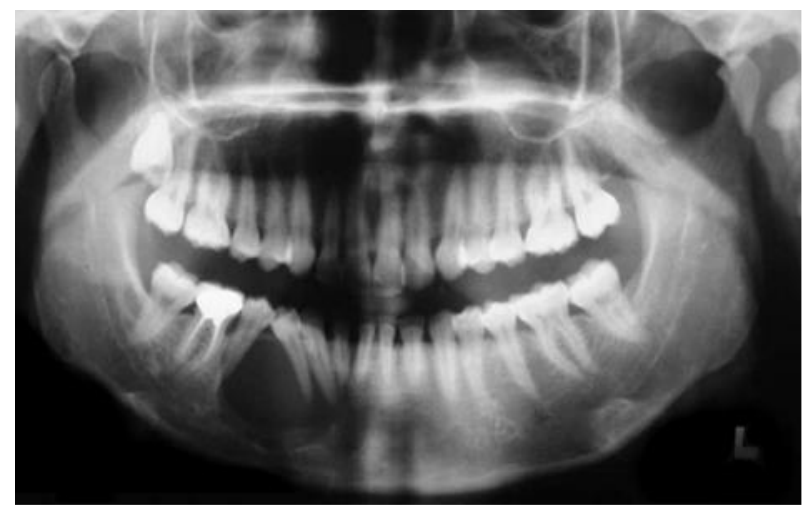

Fig. 1: Digital Panoramic Radiograph Reveals Triangular Radiolucent Area Involving Roots of Mandibular Right First and Second Premolar.

Histological examination (Figures 2.a -b) revealed a proliferation of mature stratified squamous epithelial islands in a dense fibrous connective stroma and the diagnosis of SOT was confirmed.

(A)

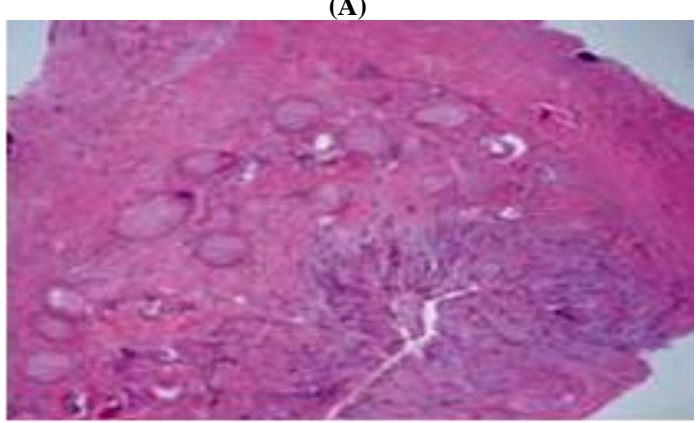

(B)

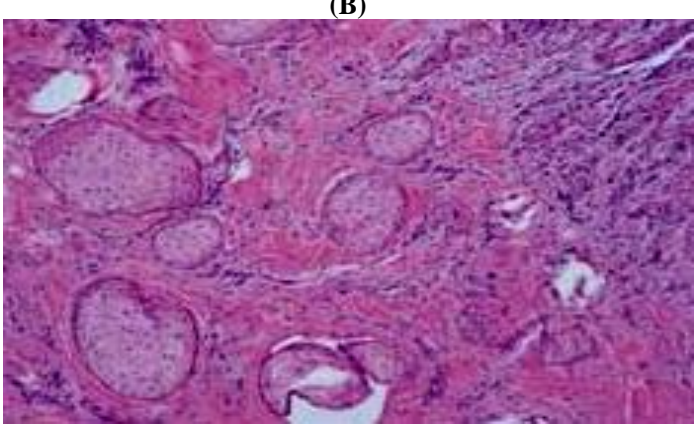

Fig. 2: (A-B) Epithelial Islands of Well-Defined Squamous Epithelium with Benign Features (Haematoxylin and Eosin Stain, Original Magnification X40 and X100)

\section{Discussion}

Odontogenic tumors arise from epithelial tissue, mesenchymal tissue, or both, which are involved in teeth development. The etiopathogenesis of these tumors and their causes or triggers are not well understood. Clinically, most of these tumors are asymptomatic, but tooth mobility, expansion and bone loss can be observed (Jones et al. 2011, Badni et al. 2012, Bansal \& Joshi 2013).

Forty-nine cases of SOT have so far been reported in the English literature (PubMed Database). Adults are affected more frequently, but the cases reported comprise a wide age-range (8-74 years), with a mean age about 38 years. There is no gender preference for SOT, the male to female ratio is $1: 1.8$. Squamous odontogenic tumors tend to arise in the canine-premolar area of the maxilla and in the molar region of the mandible, but it can occur along the jaws (Schwartz-Arad 1990). In the present case, the tumor involved the mandibular bicuspid region, causing esthetic impairment but no painful symptoms. Most cases of SOT arise and develop in the periodontium of the permanent dentition. Pullon et al. reported a case associated with the deciduous dentition and cases involving edentulous areas ((Pullon et al. 1975). The present case is the $49^{\text {th }}$ case of SOT reported in the English literature. The location of SOT in the bicuspid region is uncommon.

A typical clinical image of SOT is a slowly growing central lesion that is nearly asymptomatic. Mild pain may coexist with slight swelling of the alveolar process and mobility of the neighboring teeth, an accidental discovery in a routine radiograph is not uncommon (Barrios et al. 2004). In our case, the patient only complained of mobility of teeth in the right bicuspid region of the mandible. Upon examination a mild degree of expansion of the facial surface was revealed. Although not pathognomonic, most SOTs are detected during routine radiographic examination as a radiolucent, unilocular, triangular-shaped image associated with the roots of adjacent teeth (Ruhin et al. 2007).

Upon describing the histopathology of a typical SOT, benign squamous epithelial islands are seen, the squamous cells occupy the entire island with no columnar cells at the periphery neither palisading of the nuclei. These features enable the observers to eliminate the diagnosis of an ameloblastoma with squamous metaplasia as a differential one (Ruhin et al. 2007). The epithelial islands might be surrounded with fibrous tissue condensation together with fibroblasts, which are considered a mesenchymal reaction to epithelial proliferation.

The precise histological picture, seen in our pathology lab, conforms to the classic picture mentioned above and this led us to the definite diagnosis.

Treatment of SOT consists of conservative surgical removal (local excision), enucleation and/or complete curettage. In this case we start with initial biopsy to confirm diagnosis then go to full enucleation with curettage followed with grafting the defect using demineralized freeze-dried bone allograft and collagen membrane. The patient is currently under periodic clinical and radiological controls in order to detect any possible relapse.

\section{Conclusion}

Squamous odontogenic tumor is a benign odontogenic true neoplasm. It is viewed as a particular element, its behavior differs from being well circumscribed and locally invasive, especially in maxilla. It should be treated first conservatively, but upon recurrence a more aggressive line of treatment is to be followed. Very uncommon malignant transformation is reported. An opportune diagnosis, depending on the histologic features should be ascertained.

\section{Conflicts of interest}

The authors report no conflicts of interest related to this study. 


\section{References}

[1] Pullon PA, Shafer WG, Elzay RP, Kerr DA, Corio RL. Squamous odontogenic tumor. Report of six cases of a previously undescribed lesion. Oral Sur Oral Med Oral Pathol. 1975; 40:616-30. https://doi.org/10.1016/0030-4220(75)90372-2.

[2] Goldblatt LI, Brannon RB, Ellis GL. Squamous odontogenic tumor. Report of five cases and review of the literature. Oral Sur Oral Med Oral Pathol. 1982; 54:187-96. https://doi.org/10.1016/00304220(82)90216-X.

[3] Oliveira JA, Costa IM, Loyola AM. Squamous Odontogenic tumour like proliferations (SOT-LK) versus intra osseous squamous carcinoma in residual cyst. J Oral Maxillofac Surg 2006 Aug; 64(8):1325. https://doi.org/10.1016/j.joms.2006.04.026.

[4] Ruhin B, Raoul G, Kolb F, et al. Aggressive maxillary squamous odontogenic tumour in a child: Histological dilemma and adaptive surgical behavior. Int J Oral Maxillofac Surg 2007 Sep; 36(9):8646. https://doi.org/10.1016/j.ijom.2007.03.002.

[5] Barnes L, Everson JW, Reichart P, Sidransky D, Eds. World Health Organization Classification of Tumors. Pathology and Genetics of Head and Neck Tumors, Lyon: IARC Press 2005.

[6] Badni M, Nagaraja A, Kamath V. Squamous odontogenic tumor: a case report and review of literature. J Oral Maxillofac Pathol 2012; 16: 113-7. https://doi.org/10.4103/0973-029X.92986.

[7] Bansal S, Joshi SK. Squamous odontogenic tumor with unusual localization and appearance: a rare case report. Case Rep Med 2013; 2013: 407967. https://doi.org/10.1155/2013/407967.

[8] Adebiyi KE, Odukoya O, Taiwo EO. Squamous odontogenic tumour: Report of five cases from Nigeria and review of literature. African journal of oral health $2006 ;(1-2): 1-5$.

[9] Tarsitano A, Agosti R, Marchetti C. The diagnostic and surgica management of a multifocal calcifiyng epithelial odontogenic tumor in the mandible and maxilla associated with a squamous odontogenic tumor: first reported case in the literature. Oral Surg Oral Med Oral Pathol Oral Radiol. 2012; 113(4): e6-11. https://doi.org/10.1016/j.tripleo.2011.07.009.

[10] Parmar RM, Brannon RB, Fowler CB. Squamous odontogenic tumor-like proliferations in radicular cysts. A clinicopathologic study of forty-two cases. J Endod. 2011; 37:623-6. https://doi.org/10.1016/j.joen.2011.02.010.

[11] Jones BE, Sarathy AP, Ramos MB, Foss RD. Squamous odontogenic tumor. Head Neck Pathol. 2011; 5(1): 17-9. https://doi.org/10.1007/s12105-010-0198-y.

[12] Schwartz-Arad D, Lustmann J, Ulmansky M. Squamous odontogenic tumor. Review of the literature and case report. Int J Ora Maxillofac Surg.1990; 19(6): 327-30. https://doi.org/10.1016/S0901-5027(05)80073-6.

[13] Barrios TJ, Sudol JC, Cleveland DB. Squamous dontogenic tumor associated with an erupting maxillary canine: Case report. J Ora Maxillofac Surg $2004 \quad$ Jun; 62(6):742-4. https://doi.org/10.1016/j.joms.2003.12.014. 